\title{
EXISTENCE, UNIQUENESS AND CONTINUATION \\ OF SOLUTION OF A SUB DIFFUSION FUNCTIONAL DIFFERENTIAL EQUATIONS WITH AN INTEGRAL CONDITION
}

\section{SYED ABBAS}

Abstract. In this work, we consider a sub-diffusion functional differential equation with an integral condition. We apply the method of semidiscretization in time, to establish the existence and uniqueness of solutions. We also study the continuation of the solution to the maximal interval of existence. By using Rothe's sequence and values of the fractional integrals over time steps, the results are obtained.

Mathematics subject classification (2010): 35R11, 65M20, 34K28.

Keywords and phrases: Fractional diffusion equation, Rothe method, weak solution.

\section{REFERENCES}

[1] R.A. Adams, Sobolev Spaces, Academic Press, New York, 1975

[2] D. Bahuguna, S. ABbAs, J. DABAs, Partial functional differential equation with an integral condition and applications to population dynamics, Nonlinear Analysis: Theory, Methods and Applications 69, 8 (2008), 2623-2635.

[3] D. Bahuguna And V. Raghavendra, Application of Rothe's method to nonlinear Schrodinger type equations, Appl. Anal. 31 (1988), 149-160.

[4] D. Bahuguna And R.K. Shukla, Partial functional differential equations and applications to population dynamics, Nonlinear Dyn. Syst. Theory 5, 4 (2005), 345-356.

[5] A. Bouziani And N. MerazGa, Rothe time-discretization method applied to a quasilinear wave equation subject to integral conditions, Adv. Difference Equ. 3 (2004), 211-235.

[6] J.R. CANnON, The solution of the heat equation subject to the specification of energy, Quart. Appl. Math. 21 (1963), 155-160.

[7] Y. CHEN, CHANG-MING CHEN, Numerical method with high order accuracy for solving a anomalous subdiffusion equation, Numer. Algor. 72 (2016), 687-703.

[8] K. Fujishiro, M. Yамамото, Approximate controllability for fractional diffusion equations by interior control, Appl. Anal. 93, 9 (2014), 1793-1810.

[9] N.A. IONKIN, Solutions of boundary value problem in heat conduction theory with nonlocal boundary conditions, Differents.Urav. 13 (1977), 294-304.

[10] J. KACUR, Method of Rothe in evolution equations, Lecture Notes in Mathemathics No. 1192, Springer- Verlag/Berlin/New York/ Heidelberg, 1985, 23-34.

[11] L.I. Kamynin, A boundary value problem in the theory of the heat conduction with nonclassical boundary condition, Z. Vychisl. Mat. Fiz. 6 (1964), 1006-1024.

[12] L. Maнto, S. AвBAs, Approximate controllability and existence of optimal control of impulsive fractional semi linear functional differential equations with non-local condition, Journal of Abstract Differential Equations and Applications 4, 2 (2013), 44-59.

[13] N. Merazga And A. Bouziani, Rothe time-discretization method for a nonlocal problem arising in thermoelasticity, J. Appl. Math. Stoch. Anal. 1 (2005), 13-28.

[14] N. MERAZGA AND A. BouZIANI, Rothe method for a mixed problem with an integral condition for the two dimensional diffusion equation, Abstract and applied analysis 16 (2003), 899-922.

[15] R. MEtZleR, J. KLAFTER, The random walk's guide to anomalous diffusion: a fractional dynamics approach, Physics reports 339, 1 (2000), 1-77. 
[16] I. Podlubny, Fractional Differential Equations, Academic Press, San Diego, 1999.

[17] L.S. PUlKINA, A non-local problem with integral conditions for hyperbolic equations, Electronic Journal of Differential equations 45 (1999), 1-6.

[18] S.G. Samko, A.A. Kilbas, O.I. Marichev, Fractional Integrals and Derivatives, Gordon and Breach Science Publishers, Philadelphia, 1993.

[19] Q. TANG, Q. MA, Variational formulation and optimal control of fractional diffusion equations with Caputo derivatives, Advances in Difference Equations (2015).

[20] M. Turyn, A partial functional differential equation, J. Math. Anal. Appl. 263 (2001), 1-13.

[21] W. WAng, Y. Zhou, M. FeCKAn, Abstract Cauchy problem for fractional differential equations, Nonlinear Dynamics 71, 4 (2013), 685-700.

[22] J.R. WANG, Y. ZHOU, M. FECKAN, On the nonlocal Cauchy problem for semilinear fractional order evolution equations, Central European Journal of Mathematics 12, 6 (2014), 911-922. 